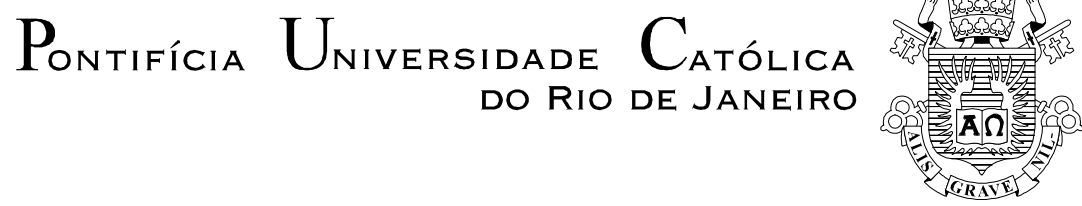

Lindomar Tiago Rodrigues

A condenação do Estado brasileiro pela Corte Interamericana de Direitos Humanos no caso da Guerrilha do Araguaia e a interpretação do Supremo Tribunal Federal sobre a Lei de Anistia Brasileira

Dissertação de Mestrado

Dissertação apresentada ao Programa de PósGraduação em Direito da PUC-Rio como requisito parcial para obtenção do título de Mestre em Direito.

Orientador: Prof. José María Gómez 


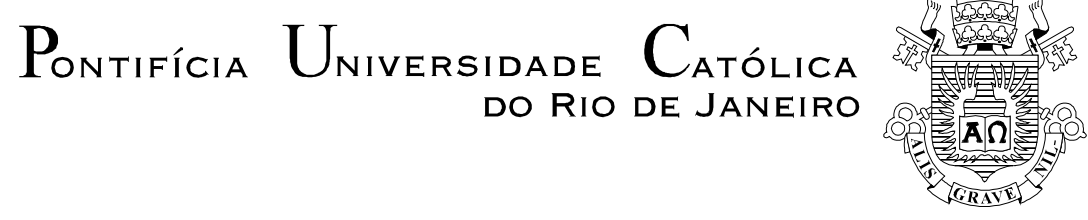

Lindomar Tiago Rodrigues

\begin{abstract}
A condenação do Estado brasileiro pela Corte Interamericana de Direitos Humanos no caso da Guerrilha do Araguaia e a interpretação do Supremo Tribunal Federal sobre a Lei de Anistia Brasileira
\end{abstract}

Dissertação apresentada ao Programa de PósGraduação em Direito da PUC-Rio como requisito parcial para obtenção do título de Mestre em Direito. Aprovada pela Comissão Examinadora abaixo assinada.

Prof. José María Gómez

Orientador

Departamento de Direito da PUC-Rio

Prof. Gisele Cittadino

Departamento de Direito da PUC-Rio

Prof. Giuseppe Mario Cocco

Escola de Serviço Social da UFRJ

Profa. Mônica Herz

Vice-Decana de Pós-Graduação do Centro de

Ciências Sociais - PUC-Rio

Rio de Janeiro, 11 de abril de 2012 
Todos os direitos reservados. É proibida a reprodução total ou parcial do trabalho sem autorização da universidade, do autor e do orientador.

\section{Lindomar Tiago Rodrigues}

Graduou-se em Direito na Universidade Federal de Uberlândia em 2004, onde se especializou em Direito Público em 2006. É Promotor de Justiça no Estado de Mato Grosso do Sul desde 2008.

Ficha Catalográfica

Rodrigues, Lindomar Tiago.

A condenação do Estado brasileiro pela Corte Interamericana de Direitos Humanos no caso da Guerrilha do Araguaia e a interpretação do Supremo Tribunal Federal sobre a Lei de Anistia Brasileira / Lindomar Tiago Rodrigues; orientador: Prof. José María Gómez. - Rio de Janeiro: PUC; Departamento de Direito, 2012.

132 f.: il. ; $29,7 \mathrm{~cm}$

1. Dissertação (mestrado) - Pontifícia Universidade Católica do Rio de Janeiro, Departamento de Direito.

Inclui referências bibliográficas.

Direitos Humanos. Justiça de Transição. Lei de Anistia. Corte Interamericana de Direitos Humanos. Guerrilha do Araguaia. I. Rodrigues, Lindomar Tiago. II Pontifícia Universidade Católica do Rio de Janeiro. Departamento de Direito. III. Título. 


\section{Agradecimento}

Agradeço a Deus pela conclusão de mais esta etapa da minha formação acadêmica e profissional.

Minha gratidão pelo apoio incondicionalde meus pais, Marcos e Sebastiana, meu irmão, Sinomar, minha namorada, Fernanda, e meus sogros, Ronaldo e Maria Emília. Foi em vocês que encontrei o incentivo e a confiança necessários para persistir. Muito obrigado.

Meus agradecimentos ao meu orientador, Professor Doutor José MaríaGoméz, cujo carisma e competênciapermitiram um ambiente propício à reflexão e ao desenvolvimento acadêmico.

Agradeço à Procuradoria-Geral de Justiça de Mato Grosso do Sul, na pessoa da Procuradora-Geral Adjunta de Justiça Irma Vieira de Santana e Anzoategui, pela sensibilidade ao autorizar a realização do curso de mestrado.

Da mesma forma, minha gratidão à Promotora de Justiça Jaceguara Dantas da Silva Passos, cuja brilhante e inédita iniciativa enquanto diretora da Fundação Escola do Ministério Público do Estado de Mato Grosso do Sul tornou possível para mim e muitos outros profissionais do direito em Mato Grosso do Sul realizar o programa de mestrado sem o afastamento das respectivas funções, o que até então era um sonho distante.

Meu muito obrigado à Pontifícia Universidade Católica do Rio de Janeiro -PUCRio, ao Departamento de Pós-Graduação em Direito, a todos os professores e a todos os colegas do curso de mestrado, pelos inúmeros momentos especiais. 


\section{Resumo}

Rodrigues, Lindomar Tiago; Gómez, José Maria. A condenação do Estado brasileiro pela Corte Interamericana de Direitos Humanos no caso da Guerrilha do Araguaia e a interpretação do Supremo Tribunal Federal sobre a Lei de Anistia Brasileira. Rio de Janeiro, 2012. 132p. Dissertação de Mestrado - Departamento de Direito, Pontifícia Universidade Católica do Rio de Janeiro.

Esta pesquisa propõe-se a confrontar a decisão tomada pelo Supremo Tribunal Federal no julgamento da ADPF 153, com a posterior e divergente sentença da Corte Interamericana de Direitos Humanos proferida no caso Gomes Lund e outros vs. Brasil, referente ao evento conhecido como Guerrilha do Araguaia. Ambas as decisões envolvem a temática da justiça de transição no Brasil e analisaram a extensão e validade da anistia concedida pela Lei 6.683/79 às violações de direitos humanos ocorridas durante o regime militar brasileiro. Os resultados desses julgamentos, porém, foram fundamentalmente opostos. O STF, em abril de 2010, declarou a constitucionalidade e eficácia da Lei de Anistia brasileira, mantendo (e reafirmando) a interpretação oficial, que perdura desde 1979, de que essa lei obstaculiza o julgamento dos crimes comuns praticados por agentes da repressão contra civis durante o regime militar. Posteriormente e de modo contrário, a CIDH, em novembro de 2010, expressamente declarou carente de efeitos jurídicos essa mesma legislação e responsabilizou internacionalmente o Estado brasileiro por sua postura anistiante. $\mathrm{O}$ estudo se inicia demonstrando a vinculação jurídica do Estado brasileiro ao aparato normativo internacional dos direitos humanos, nos planos global e regional, e sua submissão à jurisdição da Corte Interamericana. Na seqüência, evidencia os fundamentos utilizados para sustentar as confrontantes decisões do STF e da CIDH. Por fim, traça uma análise acerca dos resultados desses dois julgamentos e suas conseqüências para o trato da justiça de transição no Brasil, nos seus aspectos de justiça, verdade, memória, reparação e reformas institucionais.

\section{Palavras-chave}

Direitos Humanos; Justiça de Transição; Lei de Anistia; Corte Interamericana de Direitos Humanos; Supremo Tribunal Federal; Ditadura Militar. Guerrilha do Araguaia. 


\section{Abstract}

Rodrigues, Lindomar Tiago. The brazilian State's condemnation by the Inter-American Court of Human Rights in the Araguaia Guerrilla case and the Supreme Federal Court's interpretation about the brazilian Amnesty Law. Rio de Janeiro, 2012. 132p. MSc. Dissertation Departamento de Direito, Pontifícia Universidade Católica do Rio de Janeiro.

This research proposes to confront the decision of the Brazil's Supreme Federal Court in the ADPF 153's judgment with the subsequent and divergent sentence of the Inter-American Court of Human Rights handed down in the case Gomes Lund and others vs. Brazil, refered to the event known as Araguaia Guerrilla. Both decisions involve the theme of Brazil's transitional justice and analyzed the extent and validity of the amnesty granted by Law $6.683 / 79$ to human rights violations, occurred during the brazilian military regime. The results of these trials, however, were fundamentally opposite to each other. Brazil's Supreme Federal Court, in April of 2010, declared the constitutionality and efficacy of the brazilian Amnesty Law, maintaining (and reaffirming) the official interpretation, tha lasts since 1979, that this law doesn't allow the prosecution of ordinary crimes committed by agents of repression against civilians during the military regime. Afterwards and in a contrary way, the Inter-American Court of Human Rights, in November of 2010, expressly declared that the same law has no legal effects and blamed the brazilian State internationally, precisely because of its amnestied stance. The study starts demonstrating the legal linkage of the the brazilian State to the international legal apparatus of human rights, at the global and regional levels, and its submission to the Inter-American Court's jurisdiction. Subsequently, it evidences the arguments used to support the oppositte deciosions of the SFC and the IACHR. Finally, it outlines an analysis about those two judgements and their consequences for the treatment of transitional justice in Brazil, considering its aspects of justice, truth, memory, reparation and institutional reforms.

\section{Keywords}

Human Rights; Transitional Justice; Amnesty Law; Inter-American Court of Human Rights; Supreme Federal Court; Military Regime; Araguaia Guerrilla. 


\section{Abreviaturas}

ADPF Arguição de Descumprimento de Preceito Fundamental

ARENA Aliança Renovadora Nacional

Art.

Artigo

$\mathrm{CF}$

Constituição Federal

$\mathrm{CIDH}$

Corte Interamericana de Direitos Humanos

CODI

Centro de Operações de Defesa Interna

DJ

Diário da Justiça

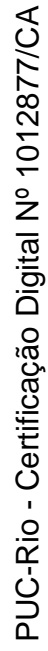

DOI

Destacamento de Operações de Informações

DOPS

Departamento de Ordem Política e Social

EC

Emenda Constitucional

ESG

Escola Superior de Guerra

$\mathrm{OAB}$

Ordem dos Advogados do Brasil

OEA

Organização dos Estados Americanos

ONU Organização das Nações Unidas

PCdoB Partido Comunista do Brasil

STF Supremo Tribunal Federal 


\section{Sumário}

Introdução

1. Internacionalização e Universalização dos Direitos Humanos no Pós-Guerra nos Planos Global e Regional 17

1.1. A Internacionalização dos Direitos Humanos no Pós-Guerra 17

1.2. O Sistema Global de Proteção dos Direitos Humanos 24

1.3. Os Sistemas Regionais de Proteção dos Direitos Humanos 26

1.4. O Sistema Interamericano de Proteção dos Direitos Humanos 28

1.4.1. Fases evolutivas do Sistema Interamericano de Proteção dos Direitos Humanos 29

1.4.1.1. Antecedentes históricos: A Declaração Americana de Direitos e Deveres do Homem $\quad 30$

1.4.1.2. Formação: Comissão Interamericana de Direitos Humanos 31

1.4.1.3. Institucionalização: a Convenção Americana sobre

Direitos Humanos e a Corte Interamericana de Direitos Humanos $\quad 33$

1.4.1.3.1. Convenção Americana sobre Direitos Humanos 33

1.4.1.3.2. Corte Interamericana de Direitos Humanos 35

1.4.1.4. Consolidação: Construção da Jurisprudência da

Corte Interamericana de Direitos Humanos 37

1.4.1.5. Aperfeiçoamento: Fortalecimento do Sistema Interamericano 37

1.5. Os Sistemas Global e Regional e a Invalidade de Leis de Anistia em casos de Violações de Direitos Humanos

1.5.1. O Sistema Universal e a Invalidade de Leis de Anistia em casos de Violações de Direitos Humanos

1.5.2. Precedentes da Corte Interamericana de Direitos Humanos em relação às Anistias em casos de Violações de Direitos Humanos 1.5.2.1. Caso Barrios Altos vs. Peru 42

1.5.2.2. Caso Almonacid Arellano e outros vs. Chile 44

1.6. Conclusão 46 
2. Lei de Anistia no Brasil: Contexto Histórico, Edição, Alcance e Interpretação Oficial 47

2.1. Ditadura Militar no Brasil 47

2.1.1. Violações dos Direitos Humanos 50

2.2. A Anistia 52

2.3. O Recente Questionamento da Lei de Anistia 55

2.4. A Decisão do Supremo Tribunal Federal na ADPF 153

2.4.1. Fundamentos do Ministro Eros Grau, relator 57

2.4.2. Votos que acompanharam o Relator 59

2.4.2.1. Ministra Cármen Lúcia.. 60

2.4.2.2. Ministra Ellen Gracie 62

2.4.2.3. Ministro Marco Aurélio 63

2.4.2.4. Ministro Celso de Mello 64

2.4.2.5. Ministro Cezar Peluso 65

2.4.2.6. Ministro Gilmar Mendes 66

2.4.3. Votos Divergentes 67

2.4.3.1. Ministro Ricardo Lewandowski 67

2.4.3.2. Ministro Ayres Britto 69

2.5. Conclusão.

3. A Decisão da Corte Interamericana de Direitos Humanos no Caso Gomes Lund e outros vs. Brasil (Guerrilha do Araguaia) 72

3.1. Introdução 72

3.2. Contextualização da Guerrilha do Araguaia 72

3.3. Desdobramentos Judiciais da Guerrilha do Araguaia 74

3.3.1. Ação perante a Justiça Federal Brasileira 74

3.3.2. Petição à Comissão Interamericana de Direitos Humanos $\quad 77$

3.3.3. O caso perante a Corte Interamericana de Direitos Humanos $\quad 79$

3.4. A Sentença da Corte Interamericana de Direitos Humanos 81

3.5.Conclusão 88

4. Confronto entre os fundamentos utilizados nas decisões e a Justiça de Transição no Brasil 90 
4.1. Introdução 90

4.2. O Acordo Inexistente 90

4.3. A Cultura da Conciliação 94

4.4. O Direito que não está no acórdão do STF 97

4.4.1. O STF e o desprezo à sua própria jurisprudência 98

4.4.2. O Direito Internacional Ignorado 101

4.4.3. O Direito Internacional e a Incompatibilidade das

Anistias concedidas às violações de Direitos Humanos 102

4.5. Justiça de Transição no Brasil 104

4.5.1. Obrigações Impostas pela Corte Interamericana no trato da Justiça de Transição no Brasil 108

4.5.2. A Incompleta Transição Brasileira 116

5. Conclusão 124

6. Referências Bibliográficas 128 